\title{
Spontaneous rupture of incisional hernia: a rare cause of a life-threatening complication
}

\author{
R K Gupta, Sah S, Agrawal S C \\ Department of Surgery, B P Koirala Institute of Health Sciences, Dharan, Sunsari, Nepal
}

Correspondence to Gupta R K, rakesh154@yahoo.co.in

\begin{abstract}
Summary
Spontaneous evisceration is a very rare and potentially fatal complication of abdominal-wall incisional hernia. Here the authors present a case report of spontaneous evisceration in an incisional hernia in a 45-year-old female patient. Management of the condition using prosthetic mesh repair risks mesh infection, while the use of non-prosthetic repair risks recurrence of the hernia due to the absence of stout natural tissues. Use of a biological mesh for the condition seems quite plausible. Thorough saline washes of the eviscerated organ; excision of redundant/ unhealthy skin and strict adherence to the fundamental principles of hernia repair is desired in managing the condition.
\end{abstract}

\section{BACKGROUND}

An incisional hernia develops in the scar of a surgical incision. Rarely, a particularly thin-walled large incisional hernia may actually ulcerate at its fundus so that omentum/ bowel protrudes or there is even the development of an intestinal fistula. Spontaneous rupture of an abdominal hernia is very rare and usually occurs in incisional or recurrent groin hernia. ${ }^{1}$ The literature documents the occurrence of spontaneous evisceration of abdominal-wall hernias in the form of a few case reports only. More commonly, this complication has been reported among patients with tense ascites secondary to chronic liver disease. Its occurrence in the case of incisional hernia in an otherwise healthy patient has been reported only once. This case report from the $B$ P Koirala Institute of Health Sciences in Dharan, Nepal, documents a further instance of spontaneous evisceration in an incisional hernia.

\section{CASE PRESENTATION}

A 45-year-old woman presented to the surgical emergency with a loop of bowel protruding out through abdominal-wall defect following a bout of cough for 1 day. (figure 1A,B)

Five years earlier, she had undergone total hysterectomy and bilateral salpingo-oophorectomy. This was followed by wound dehiscence which was closed with through-andthrough deep tension sutures. After 1 year, she developed an incisional hernia and was given an abdominal belt and advised to lose weight. After wearing the belt for 2 years, two ulcers developed in the skin of the hernia. These were treated with local dressings and by replacement of the belt. On 26 June 2010, she presented to our hospital with protrusion of intestinal loops through the apex of the incisional hernia since the last $24 \mathrm{~h}$. The lump had slowly enlarged in size and before admission she also noticed a dragging pain in the epigastrium. This was followed by two episodes of vomiting of stomach content.

On examination, she was calm with normal temperature, pulse rate and blood pressure and without evidence of gross cardiovascular or respiratory disease. Abdominal examination revealed a large, 8 inch diameter, lower midline incisional hernia. The hernia was non-tender and was partially reducible through a wide, easily palpable defect in the abdominal wall (figure 2). The skin overlying the hernia was thinned out and a perforation, about 3 inches long, was seen in the skin. About a feet of small intestine loop was protruding outside through this defect and this loop was congested, haemorrhagic, but healthy.

\section{INVESTIGATIONS}

Blood and urine investigations were normal.

\section{TREATMENT}

The patient was operated on an emergency basis and a non-prosthetic repair was performed. During surgery, an ellipse of skin was removed together with a small cuff of adherent sac. The small intestine in the sac and extruded bowel was perfectly healthy. The eviscerated bowel was washed with normal saline before repositing it into the abdomen. Peritoneal closure was easy as only the minimum amount of sac was excised. The wound was closed over a subcutaneous drain. The drain was removed on the third postoperative day.

\section{OUTCOME AND FOLLOW-UP}

The patient made an uneventful recovery and was discharged home on the fifth postoperative day. She has been fit and healthy and completely symptom-free for last 4 months.

\section{DISCUSSION}

Spontaneous rupture of abdominal hernia is a rare event which can affect any abdominal hernia but is more commonly reported in incisional hernia and recurrent groin hernias. ${ }^{2}{ }^{3}$ Eight cases of spontaneous rupture of abdominal hernia ${ }^{2-9}$ in the adult age group have been reported in the literature so far. Hartely ${ }^{3}$ and Hamilton ${ }^{4}$ reported 


\section{BMJ Case Reports}

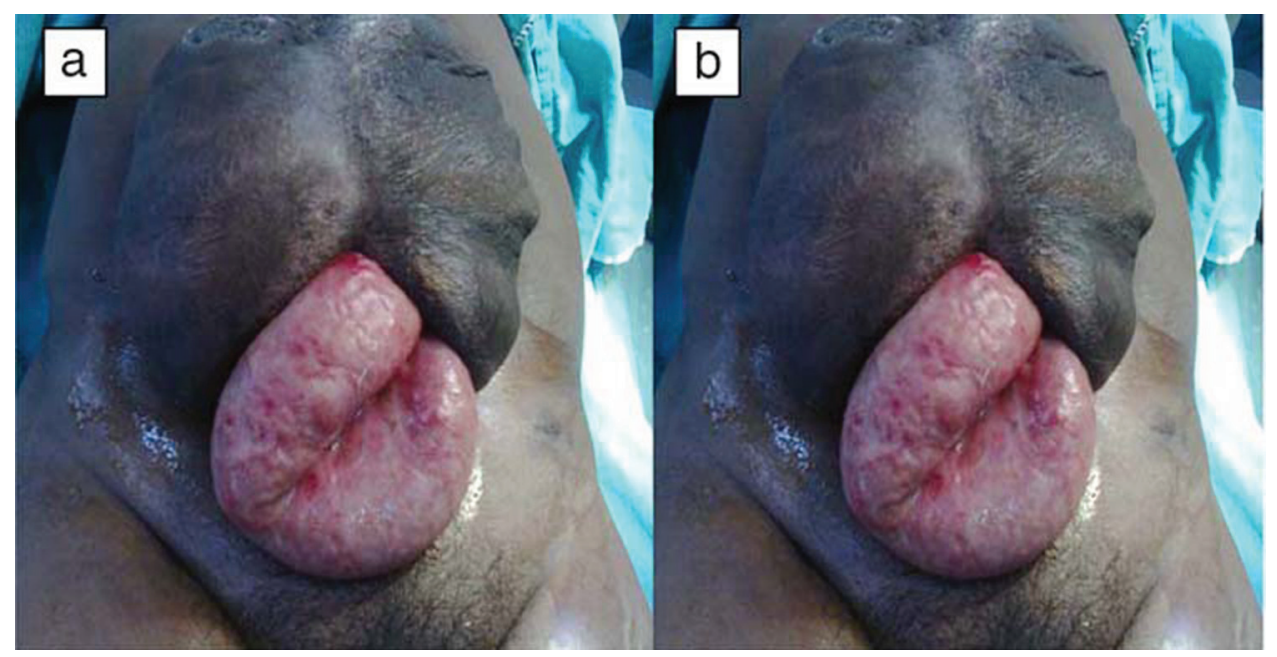

Figure 1 (A) and (B) Showing bowel loop protruding out through lower abdominal-wall defect.

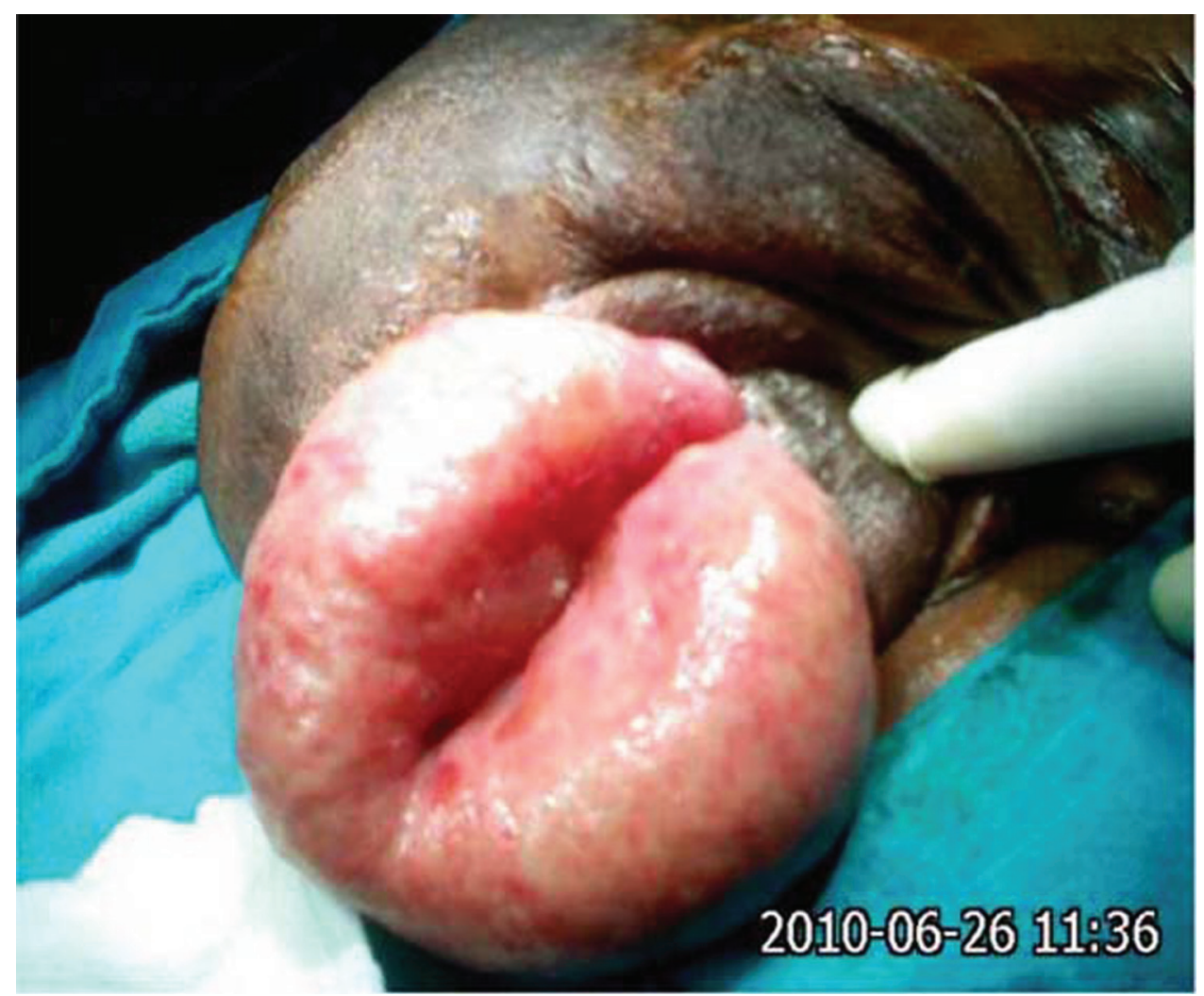

Figure 2 Showing bowel couldn't be repositioned into abdominal cavity.

rupture through lower midline incision while Aggarwal ${ }^{5}$ found herniation after upper abdominal surgery following perforated duodenal ulcer. This rupture may be sudden following increase in the intra-abdominal pressure like coughing or lifting a heavy weight, or it may be gradual after developing an ulcer at the fundus of the sac. ${ }^{4}$ In our case, rupture of the hernial sac occurred because of sudden increase in intra-abdominal pressure due to excessive coughing.

The large incisional hernia is contained only by its sac and thin atrophic and avascular skin. Larger the hernia, more atrophic and avascular is the overlying skin, and this, along with thin sac leads to higher chances of rupture of the incisional hernia. ${ }^{5}$ Various factors which can contribute to the rupture of a hernia are friction by the patient's external corset or abdominal support, thin atrophic skin, lack of any adhesions between bowel and sac, allowing the bowel to act as a hammer-head upon the skin. ${ }^{6}$

Complications such as adhesions, incarceration of bowel and intestinal obstruction, are well documented in association with incisional hernia but spontaneous rupture is very rarely reported in literature. ${ }^{7}$ After Hartely's ${ }^{3}$ report of two such cases, there have been very few case reports documented on this. The incidence of this complication is higher in developing countries compared to developed countries. ${ }^{8}$ Rarely this may lead to obstruction and 


\section{BMJ Case Reports}

strangulation of small bowel and generalised peritonitis, a potential cause of death.

Neglect for early operative intervention or delay in seeking treatment increases the risk of rupture. ${ }^{9}$ Eventration of bowel or omentum demands emergency operation. The hernial contents can either be covered primarily by mesh repair of hernia if the general condition of the patient and local condition of operative site allows or can be covered by skin followed by delayed mesh repair. ${ }^{10}$

This case report has been presented due to the rarity of this complication. We believe that appropriate early surgical management could have prevented this complication. The principle of early referral and repair of incisional hernias is the key for prevention of this complication as well as the associated morbidity and mortality.

\section{Learning points}

- Spontaneous rupture of incisional hernia is probably rarely reported.

- Primary treatment of incisional hernia is surgical repair even when asymptomatic because of its potential to develop complications.

- Early surgical treatment can prevent life-threatening complications that include adhesions, incarceration of bowel and intestinal obstruction/strangulation and rarely rupture.

- This case is also important because it highlights the social stigma attached in revealing incisional hernia in developing countries where diseases are not confessed.

\section{CONCLUSION}

Spontaneous rupture of abdominal hernia is a very rare complication, it usually occurs in cases of incisional hernias. These cases should be managed by primary repair if there is no gangrenous segment and the contamination is minimal, or by delayed repair if there is gross contamination and resection and if anastomosis is required.

Acknowledgement The authors are thankful to the Dr Sidharth Koirala, Department of anaesthesiology, B P Koirala Institute of Health Sciences, for his prompt response and input in the above case.

Competing interests None.

Patient consent Obtained.

\section{REFERENCES}

1. Zinner MJ, Schwartz SI, Ellis H. Incisions, closures, and management of the Wound. Maingot's Abdominal Surgery. Volume 1. Tenth edition. Norwalk, CT: Appleton and Lange, 1997:423.

2. Von Helwig H. Uber sonenannte spontaneous rupture von hernien. Schweiz med wschr 1958;88:662-66.

3. Hartely RC. Spontaneous rupture of incisional hernia. Br J surg 1961:49:617-18.

4. Hamilton RW. Spontaneous rupture of incisional hernia. Br J Surg 1966;53:477-79

5. Aggarwal P K. Spontaneous rupture of incisional hernia. Br J Clin Pract 1986;40:443-4

6. Singla SL, Kalra U, Singh B, et al. Ruptured incisional hernia. Trop Doct 1997:27:112-13.

7. Ogundiran TO, Ayantunde AA, Akute 00. Spontaneous rupture of incisional hernia-a case report. West Afr J Med 2001;20:176-8.

8. Sagar J, Sagar B, Shah DK. Spontaneous rupture of incisional hernia. Indian J Surg 2005;67:280-1.

9. Husain M, Mohsin M, Mir IS, et al. Spontaneous rupture of incisional hernia: a case report. Internet J Surg 2007;11:2

10. Mudge M, Hughes LE. Incisional hernia: a 10 year prospective study of incidence and attitudes. Br J Surg 1985;72:70-1.

This pdf has been created automatically from the final edited text and images.

Copyright 2011 BMJ Publishing Group. All rights reserved. For permission to reuse any of this content visit http://group.bmj.com/group/rights-licensing/permissions.

BMJ Case Report Fellows may re-use this article for personal use and teaching without any further permission.

Please cite this article as follows (you will need to access the article online to obtain the date of publication).

Gupta RK, S Sah, SC Agrawal. Spontaneous rupture of incisional hernia: a rare cause of a life-threatening complication . BMJ Case Reports 2011; 10.1136/bcr.11.2010.3486, date of publication

Become a Fellow of BMJ Case Reports today and you can:

- Submit as many cases as you like

- Enjoy fast sympathetic peer review and rapid publication of accepted articles

- Access all the published articles

- Re-use any of the published material for personal use and teaching without further permission

For information on Institutional Fellowships contact consortiasales@bmjgroup.com

Visit casereports.bmj.com for more articles like this and to become a Fellow 